\title{
The Relation Between Calcaneus Stiffness Index as a Measure of Bone Density and Body Mass Index in an Egyptian Cohort
}

This article was published in the following Dove Press journal: Journal of Multidisciplinary Healthcare

\author{
Khalid Ali iD \\ Salma MS El Said (iD ${ }^{2}$ \\ Nermien $\mathrm{N}$ Adly ${ }^{2}$ \\ Samia A Abdul-Rahman (D) ${ }^{2}$ \\ 'Academic Department of Geriatrics, \\ Brighton and Sussex Medical School, \\ Brighton, UK; ${ }^{2}$ Geriatrics and \\ Gerontology Department, Faculty of \\ Medicine, Ain Shams University, Cairo, \\ Egypt
}

Background: Obesity and osteoporosis are two conditions that are associated with morbidity and mortality; there is contradictory evidence regarding this association.

Purpose: The aim of the current study was to explore further the association between obesity and calcaneus stiffness index (CSI), as a measure of bone density, in a communitybased cross-sectional study in an Egyptian population.

Methods: A cross-sectional study was conducted among active subjects, aged $\geq 20$ years old, over one year. CSI was measured by Quantitative ultrasound (QUS), in addition; QUS T-score and Z-score of the non-dominant heel scan were recorded.

Results: Two hundred and eighty participants were recruited; 7 subjects were excluded because of $\mathrm{Z}$ score more than -2 , mean age was $61( \pm 11.9)$ years, and mean BMI was $29.7( \pm 5.6)$. Female participants were $77.7 \%$, with mean of age $60.3( \pm 11.6)$; and age range $20-82$ years. Male participants were $22.3 \%$, with mean of age 63.6 ( \pm 12.7$)$; and age range $30-80$ years. Older subjects ( $>55$ years) had significantly lower CSI and worse T-score than the younger subjects $(\mathrm{P}<0.001$ for both). In the younger age group, BMI was not significantly associated with CSI, even after adjustment for gender $(\mathrm{P}=0.52)$. However, in the older age group, $\mathrm{BMI}$ was significantly associated with stiffness index $(\mathrm{P}=0.049, \mathrm{O} . \mathrm{R} .=1.73)$, even after adjustment for gender $(\mathrm{P}=0.041, \mathrm{O} . \mathrm{R} .=1.7)$. Conclusion: Compared to young subjects, older subjects ( $\geq 55$ years) had significantly lower bone strength as measured by CSI, and their BMI was significantly positively associated with bone density. In younger people ( $<55$ years), BMI was not associated with bone strength.

Keywords: BMI, bone, obesity, QUS, stiffness index

\section{Introduction}

Osteoporosis is a systemic disease caused by low bone mass and micro-architectural deterioration of bone tissue leading to fractures that impair activities of daily living and quality of life and is also associated with mortality in the elderly. ${ }^{1,2}$

The World Health Organization defined obesity as a body mass index (BMI) $\geq 30 \mathrm{~kg} / \mathrm{m}^{2.3}$ Obesity and osteoporosis are two conditions associated with an increased prevalence in morbidity and mortality. ${ }^{4,5}$ Recent studies have shown both possible protective, ${ }^{6}$ and harmful $^{7}$ associations between obesity and osteoporosis. With a worldwide increase in both obesity and an aging population, it is important to understand the possible associations between osteoporosis and obesity. $^{8}$

Fifty percent of the obese population over the world are distributed over 10 countries, and Egypt is one of them. The obese population over the world represent
Correspondence: Salma MS El Said Geriatrics and Gerontology Department, Faculty of Medicine, Ain Shams University, Emtedad Ramsis Street, Abbasia, Cairo, Egypt Tel +20I 222202878

Email Salma_elsaid@med.asu.edu.eg 
693 million subjects, ${ }^{9}$ with a reported prevalence of osteoporosis and osteopenia between $21.9-28.4 \%$ and 26$53.9 \%$ consecutively. ${ }^{10,11}$

Previous studies reported a positive association between BMI and bone density in specific Egyptian groups such as those attending osteoporosis screening units; overweight was found to be a protective factor for both femoral and spinal osteoporosis. ${ }^{12}$ In another study including those admitted to trauma units, those with normal BMI had a higher prevalence of osteoporosis compared to overweight and obese subjects. ${ }^{13}$

Therefore, the aim of the current study was to assess the association between obesity and stiffness index, as a measure of bone fragility, ${ }^{14}$ in a community-based crosssectional study in an Egyptian population.

\section{Methodology}

Study type: A cross-sectional study was conducted among subjects attending 10 community clubs, in Cairo, Egypt.

Sample Size: Two hundred and eighty participants were recruited; 7 subjects were excluded because of $Z$ score more than -2 .

Study setting: Subjects were recruited from 10 Community Clubs in Cairo Egypt from January to December 2017.

Study duration: from 1st January to 31st December 2017. Inclusion criteria:

Ambulatory active subjects, as defined by WHO, who do at least 150 mins of moderate-intensity aerobic physical activity throughout the week ${ }^{15}$ and are willing to participate in the study were included. Age range includes all subjects above 20 years old.

Exclusion criteria:

- Less active subjects as defined by any activity level less than 150 mins of moderate-intensity aerobic physical activity throughout the week

- Use of hormone replacement therapy

- Current diagnosis of secondary osteoporosis (Z score less than cutoff -2$)^{16}$

- Those who refused to participate.

\section{Study Tools}

All study subjects had the following assessments:

\section{Anthropometric Measurements}

Anthropometric measurements were done using a scale to the nearest $0.2 \mathrm{~kg}$ and standing height was measured using a stadiometer to the nearest $0.1 \mathrm{~cm}$ wearing light clothes and no shoes on.

Body mass index (BMI) was calculated as weight divided by height squared $(\mathrm{kg} / \mathrm{m} 2)$. Overweight was defined as $25-29.9 \mathrm{~kg} / \mathrm{m}^{2}$, and obesity was defined as $\geq 30 \mathrm{~kg} / \mathrm{m}^{2}$, according to the conventional WHO classification. ${ }^{3}$

\section{Quantitative Ultrasound (QUS)}

The gold standards for measuring bone density are Dualenergy X-ray absorptiometry (DXA) and Quantitative computed tomography (QCT). ${ }^{17,18}$ However, Quantitative ultrasound (QUS) was proposed as an indirect assessment of bone quality, as this modality has the advantage of being portable, inexpensive, noninvasive with no use of ionizing radiation, in addition to comparable cost and time effectiveness compared to DXA and QCT.

As DXA and QCT provide limited information on bone structure relating to elasticity, the QUS stiffness index was suggested to assess dimensional structure and strength. ${ }^{19}$ The possible clinical applications of QUS include diagnosis of osteoporosis, monitoring of skeletal changes associated with disease prognosis and treatment, and fracture risk assessment. ${ }^{20}$ Furthermore, QUS is a strong predictor of osteoporotic fracture as $\mathrm{BMD},{ }^{17,21}$ as well as assessing other mechanical characteristics of the bone, such as elasticity, microarchitecture and strength. ${ }^{22,23}$ It can also discriminate between individuals with a low risk and high risk of having abnormal BMD in clinical settings. ${ }^{24,25}$ The two main parameters measured in QUS are: broadband ultrasound attenuation (BUA) and speed of sound (SOS). From these measures, several other measures derived such as amplitude-depend SOS, stiffness index, estimated BMD and quantitative ultrasound index. Some authors suggested that these parameters are more useful to determine subjects with diminished bone health status. ${ }^{26}$ The stiffness index was introduced to measure bone fragility and it is defined as a combination of normalized SOS and BUA ${ }^{14}$ Stiffness index was calculated by the following equation:

Stiffness index $=(0.67 \times$ BUA $)+(0.28 \times \mathrm{SOS})-420^{27}$

The calcaneus (heel) is an ideal validated anatomic site for bone mass screening using QUS method as recommended by the International Society for Clinical Densitometry. ${ }^{28}$ The majority of published literature on QUS has focused on the calcaneal site as it has a high metabolic activity and reflecting spine demineralization pattern. ${ }^{26}$

Ultrasound BMD was measured by a portable ultrasound bone densitometer (GE healthcare - Achilles, USA) 
Using high-frequency sound waves, the Achilles measures both SOS and BUA. Both measurements calculate a single index called stiffness index which was compared to reference figures for both a healthy young adult and agematched healthy adults to create the T-score and the Z-score consecutively.

Calcaneus stiffness index (CSI), QUS T-score, and $\mathrm{Z}$-score of the non-dominant heel scan were recorded.

\section{Statistical Analysis}

SPSS version 16 (SPSS Inc., Chicago, IL, USA) was used for data analysis. Qualitative data were expressed in the form of number and percentage. Quantitative data were expressed in the form of mean \pm SD or median and interquartile range. Comparison between both groups was done using ChiSquare test and independent $t$-test.

Generalized linear model was used to study the significance of anthropometric measures, especially BMI, as a predictor of CSI, after adjustment for gender.

\section{Results}

Two hundred and eighty participants were recruited to the study, 7 were excluded because of $Z$ score more than -2 . The mean age of the study subjects was $61( \pm 11.9)$ years, age range 20-82 years, and the mean BMI was 29.7 ( \pm 5.6) (Table 1). Female participants were $77.7 \%$, with mean of age 60.3 ( \pm 11.6 ); and age range $20-82$ years. Male participants were $22.3 \%$, with mean of age 63.6
( \pm 12.7); and age range $30-80$ years. Study participants were categorized according to their age into $<55$ and $\geq 55$ years old. There was no significant difference between both groups in gender distribution or BMI ( $\mathrm{P}=0.07$ and 0.08 consecutively) (Table 1$)$.

Older subjects ( $>55$ years) had significantly lower CSI and worse $\mathrm{T}$-score than younger subjects $(\mathrm{P}<0.001$ for both) (Table 2).

In the younger age group, BMI was not significantly associated with CSI, even after adjustment for gender $(\mathrm{P}=0.52)$ (Table 3).

However, in the older age group, BMI was positively associated with CSI, even after adjustment for gender $(\mathrm{P}=0.041, \mathrm{O} . \mathrm{R} .=1.7)($ Table 3$)$.

\section{Discussion}

Obesity has been thought of as a protective factor in bone health. ${ }^{11}$ However, some studies have challenged that assumption. ${ }^{6,7}$ In our study in an Egyptian cohort of 273 subjects, we found that obesity is associated with better bone dimensional structure and strength, as measured by CSI, in subjects aged $\geq 55$ years old, even after adjustment for gender. Older patients had less bone strength than the younger age group. This is in accordance with the fact that with aging there is a decrease in bone strength, as damage accumulation in devitalized bone over time decreases bone strength. ${ }^{29}$

Our findings in relation to a positive association of BMI and bone strength are in accordance with previous

Table I Basic Characteristics of the Study Participants

\begin{tabular}{|l|l|l|l|l|}
\hline Variables & All Subjects & $\leq \mathbf{5 5}$ Years Old $(\mathbf{n}=\mathbf{6 4})$ & $\mathbf{> 5 5}$ Years Old $(\mathbf{n}=\mathbf{2 0 9})$ & P value \\
\hline Age, years & $61 \pm 11.9$ & $43.5 \pm 8.3$ & $66.4 \pm 6.4$ & $<0.001$ \\
Gender, female & $212(77.7 \%)$ & $55(85.9 \%)$ & $157(75.1 \%)$ & 0.07 \\
Weight $(\mathrm{kg})$ & $80.3 \pm 13$ & $76.2 \pm 15.2$ & $81.53 \pm 12.5$ & 0.013 \\
Height $(\mathrm{cm})$ & $164.7 \pm 6.8$ & $163.8 \pm 7.2$ & $164.9 \pm 6.7$ & 0.28 \\
BMI $\left(\mathrm{Kg} / \mathrm{m}^{2}\right)$ & $29.7 \pm 5.6$ & $28.5 \pm 6.4$ & $30.1 \pm 5.3$ & 0.08 \\
\hline
\end{tabular}

Table 2 Bone Indices and Obesity Distribution Among the Studied Groups

\begin{tabular}{|l|l|l|l|l|}
\hline Variables & All Subjects & $\leq \mathbf{5 5}$ Years Old $(\mathbf{n}=\mathbf{6 4})$ & $\mathbf{> 5 5}$ Years Old $(\mathbf{n = 2 0 9 )}$ & $\mathbf{P}$ value \\
\hline Stiffness index & $84.8 \pm 19$ & $93.95 \pm 15.9$ & $82.1 \pm 20.1$ & $<0.001$ \\
\hline T-score & $-0.9 \pm 1.2$ & $-0.3 \pm 1$ & $-1.07 \pm 1.2$ & $<0.001$ \\
\hline $\begin{array}{l}\text { Osteoporosis } \\
\text { (T score } \leq-2.5)\end{array}$ & $27(9.9 \%)$ & $1(1.6 \%)$ & $26(12.4 \%)$ & 0.008 \\
\hline Obese & $120(44 \%)$ & $23(35.9 \%)$ & $97(46.4 \%)$ & 0.3 \\
\hline Overweight & $105(38.5 \%)$ & $27(42.2 \%)$ & $78(37.3 \%)$ & \\
\hline
\end{tabular}


Table $3 \mathrm{BMI}$ as Predictor/Associate of Stiffness Index in Subjects $<55$ and $\geq 55$ Years Old

\begin{tabular}{|l|l|l|l|}
\hline & O.R. & 95\% C.I. & P value \\
\hline $\begin{array}{l}\text { BMI } \\
\quad<55 \text { years old } \\
\geq 55 \text { years old }\end{array}$ & & & \\
\hline $\begin{array}{l}\text { BMI, after adjustment for gender } \\
<55 \text { years old } \\
\geq 55 \text { years old }\end{array}$ & 1.73 & $1.001-3.015$ & 0.049 \\
\hline
\end{tabular}

literature in older subjects; ${ }^{6,11,12}$ Papakitsou et al found that BMI is inversely associated with levels of collagen I, as a bone degradation marker. ${ }^{30}$ These data are also supported by Shen et al who linked BMI to a higher integral, trabecular and cortical BMD and percent cortical volume. ${ }^{31}$ Similarly, Scott et $\mathrm{al}^{7}$ found a positive impact of BMI on BMD in older subjects.

Furthermore, muscle mass measures adjusted for height was associated with less incident osteoporosis in postmenopausal women, as reported by Papageorgiou et al. ${ }^{32}$

Some studies have shown conflicting evidence; a wide based study among women with mean age of 62.08 years found no strong association between BMI and BMD. However, Matijevic et al study in their analysis combined all subjects aged from 30 to 79 years without differentiating between older and younger subjects. ${ }^{33}$

Although Matijevic et al did not find a strong association between BMI and BMD, the association was stronger with BMD of the total hip than BMD of the lumbar spine.

On the other hand,. other findings suggest that obesity may not be beneficial to the bone health. Some researchers have shown that a higher body mass has a significant risk for fragility fracture, especially for fractures occurring at sites other than hip. ${ }^{34}$

In our study obesity was not associated with bone dimensional structure and strength, even after adjustment for gender in subjects aged $<55$ years. This finding is in agreement with Janicka et $\mathrm{al}^{35}$ who found that fat mass is not beneficial to bone health in young adults.

Zhao et al Study ${ }^{36}$ conducted among Caucasian and Chinese subjects and were analyzed separately, subjects were premenopausal women and adult men; mean age, $27.2 \pm 4.5$ years; range, 19.6-45.1 yr. BMI was a significant predictor of BMD; however, the standardized beta coefficient was only 0.23 for lumbar spine and 0.25 for femoral neck in Caucasian. Furthermore, fat mass was inversely correlated with bone mass.
Chen et al conducted their study among Asian adult males and females, aged $\geq 20$ years, and reported beneficial effect of obesity on $\mathrm{BMD},{ }^{37}$ where rare cases of osteoporosis were reported as the current work. Racial-based data and the use of 27 as cutoff for BMI might underlie the difference with our Egyptian data.

On the other hand, a wide based study among women with mean age of 52.7 years, age range from 40 to 59 years, reported a negative impact of low BMI on bone health, ${ }^{38}$ however, they included only those with criteria eligible for DEXA testing.

At the tissue level, in premenopausal women, obese subjects, as defined by central adiposity, had lower bone quality and stiffness and markedly diminished bone formation; however, there was a lack of relationships between trunk fat and BMD. ${ }^{39}$

In a population with mean age of 44 years old, it was noted that overweight was neutral or protective for BMD, while obesity was associated with a low bone mass indicating osteoporosis.

Further controversy was raised by Chen et al, ${ }^{40}$ as percent body fat in adults was associated with reduced BMD in metabolic healthy obese subjects indicating that body fat might be a useful indicator for low BMD. A gender difference was noted, reflecting that hormones might influence bone metabolism which deserves further investigation into the possible pathophysiological mechanisms.

\section{Conclusion}

Compared to young subjects, older subjects ( $\geq 55$ years) had significantly lower bone strength as measured by CSI, and their BMI was significantly associated with bone density. In younger people ( $<55$ years), BMI was not associated with bone strength.

\section{Ethical Consideration}

All procedures performed in studies involving human participants were in accordance with the ethical standards of the institutional and/or national research committee and with the 1964 Helsinki declaration and its later amendments or comparable ethical standards. The study methodology was reviewed and approved by the Research Review Board of the Geriatrics and Gerontology Department, Faculty of Medicine, Ain Shams University. Informed verbal consent was obtained from all individual participants included in the study. Verbal consent was relied upon as a large percent of subjects is illiterate, the 
ethic committee approved the use of verbal consent, and the verbal consent was documented by the presence of a next of kin and a nurse.

\section{Disclosure}

The authors declare that they have no conflict of interest in this work.

\section{References}

1. Muraki S, Yamamoto S, Ishibashi H, Nakamura K. Factors associated with mortality following hip fracture in Japan. J Bone Miner Metab. 2006;24(2):100-104. doi:10.1007/s00774-005-0654-z

2. Johnell O, Kanis JA, Odén A, et al. Mortality after osteoporotic fractures. Osteoporos Int. 2004;15(1):38-42. doi:10.1007/s00198003-1490-4

3. WHO. Obesity and Overweight. World Health Organization. 2018 [Updated February 16 2018]. Available from: https://www.who.int/en/ news-room/fact-sheets/detail/obesity-and-overweight. Accessed March 15, 2019.

4. Greco EA, Lenzi A, Migliaccio S. The obesity of bone. Ther Adv Endocrinol Metab. 2015;6(6):273-286. doi:10.1177/2042018815611004

5. WHO. Obesity: Preventing and Managing the Global Epidemic; WHO; Geneva, 2000.

6. Mazocco L, Chagas P. Association between body mass index and osteoporosis in women from northwestern Rio Grande do Sul. Rev Bras Reumatol Engl Ed. 2017;57(4):299-305. doi:10.1016/j.rbr.2016.07.009

7. Scott D, Chandrasekara SD, Laslett LL, Cicuttini F, Ebeling PR, Jones G. Associations of sarcopenic obesity and dynapenic obesity with bone mineral density and incident fractures over 5-10 years in community-dwelling older adults. Calcif Tissue Int. 2016;99 (1):30-42. doi:10.1007/s00223-016-0123-9

8. Nielson CM, Srikanth P, Orwoll ES. Obesity and fracture in men and women: an epidemiologic perspective. J Bone Miner Res. 2012;27 (1):1-10. doi:10.1002/jbmr.1486

9. Ng M, Fleming T, Robinson M, et al. Global, regional, and national prevalence of overweight and obesity in children and adults during 1980-2013: a systematic analysis for the Global Burden of Disease Study 2013. Lancet. 2014;384(9945):766-781. doi:10.1016/S01406736(14)60460-8

10. Taha M. Prevalence of osteoporosis in Middle East systemic literature review. Paper presented at: 10th ECOO; 2011; Cairo, Egypt.

11. Gheita TA, Hammam N. Epidemiology and awareness of osteoporosis: a viewpoint from the Middle East and North Africa. Int J Clin Rheumtol. 2018;13(Special Issue: Epidemiology of Osteoporosis):134-147.

12. Abd-Al-Aty M. Regional fat, weight and osteoporosis in elderly women in Egypt. East Mediterr Health J. 2011;17(11):850-854.

13. Farouk O, Mahran DG, Said HG, et al. Osteoporosis among hospitalized patients with proximal femoral fractures in Assiut University Trauma Unit, Egypt. Arch Osteoporos. 2017;12(1):12. doi:10.1007/ s11657-017-0308-5

14. Takeda N, Miyake M, Kita S, Tomomitsu T, Fukunaga M. Sex and age patterns of quantitative ultrasound densitometry of the calcaneus in normal Japanese subjects. Calcif Tissue Int. 1996;59(2):84-88. doi: $10.1007 / \mathrm{s} 002239900091$

15. WHO. Global Recommendations on Physical Activity for Health. Organization WH; 2010:60.

16. Sheu A, Diamond T. Diagnostic tests: secondary osteoporosis. Aust Prescr. 2016;39(3):85-87.

17. Gregg EW, Kriska AM, Salamone LM, et al. The epidemiology of quantitative ultrasound: a review of the relationships with bone mass, osteoporosis and fracture risk. Osteoporos Int. 1997;7(2):89-99. doi:10.1007/BF01623682
18. Njeh CF, Boivin CM, Langton CM. The role of ultrasound in the assessment of osteoporosis: a review. Osteoporos Int. 1997;7 (1):7-22. doi:10.1007/BF01623454

19. Glüer C-C, GROUP FTIQUC. Quantitative ultrasound techniques for the assessment of osteoporosis: expert agreement on current status. J Bone Miner Res. 1997;12(8):1280-1288. doi:10.1359/jbmr.1997. 12.8.1280

20. Hans D, Arlot ME, Schott AM, Roux JP, Kotzki PO, Meunier PJ. Do ultrasound measurements on the os calcis reflect more the bone microarchitecture than the bone mass?: a two-dimensional histomorphometric study. Bone. 1995;16(3):295-300. doi:10.1016/8756-3282(94)00041-7

21. Moayyeri A, Adams JE, Adler RA, et al. Quantitative ultrasound of the heel and fracture risk assessment: an updated meta-analysis. Osteoporos Int. 2012;23(1):143-153. doi:10.1007/s00198-011-1817-5

22. Lin JD, Chen JF, Chang HY, Ho C. Evaluation of bone mineral density by quantitative ultrasound of bone in 16,862 subjects during routine health examination. Br J Radiol. 2001;74(883):602-606. doi:10.1259/bjr.74.883.740602

23. Sakata S, Barkmann R, Lochmüller E-M, Heller M, Glüer -C-C. Assessing bone status beyond BMD: evaluation of bone geometry and porosity by quantitative ultrasound of human finger phalanges. J Bone Miner Res. 2004;19(6):924-930. doi:10.1359/JBMR.040131

24. Albanese CV, Cepollaro C, de Terlizzi F, Brandi ML, Passariello R. Performance of five phalangeal QUS parameters in the evaluation of gonadal-status, age and vertebral fracture risk compared with DXA. Ultrasound Med Biol. 2009;35(4):537-544. doi:10.1016/j. ultrasmedbio.2008.09.027

25. Omodei U, Benussi C, Ramazzotto F, Feller M, Gambacciani M. Risk identification of osteoporosis in postmenopausal women by a simple algorithm based on ultrasound densitometry and body mass index. J Clin Densitom. 2008;11(3):412-416. doi:10.1016/j.jocd.2008.01.003

26. Knapp KM. Quantitative ultrasound and bone health. Salud Publica Mex. 2009;51(Suppl 1):S18-24. doi:10.1590/S0036-36342009000700005

27. Gudmundsdottir SL, Indridason OS, Franzson L, Sigurdsson G. Agerelated decline in bone mass measured by dual-energy X-ray absorptiometry and quantitative ultrasound in a population-based sample of both sexes: identification of useful ultrasound thresholds for osteoporosis screening. J Clin Densitom. 2005;8(1):80-86. doi:10.1385/JCD:8:1:080

28. ISCD. 2015 ISCD official positions - adult. The International Society for Clinical Densitometry. 2015 [Updated June 18, 2015]. Available from: https://www.iscd.org/official-positions/2015-iscd-officialpositions-adult/. Accessed March 15, 2019.

29. Burr DB. Bone material properties and mineral matrix contributions to fracture risk or age in women and men. $J$ Musculoskelet Neuronal Interact. 2002;2(3):201-204.

30. Papakitsou EF, Margioris AN, Dretakis KE, et al. Body mass index (BMI) and parameters of bone formation and resorption in postmenopausal women. Maturitas. 2004;47(3):185-193. doi:10.1016/ S0378-5122(03)00282-2

31. Shen J, Nielson CM, Marshall LM, Lee DC, Keaveny TM, Orwoll ES. The association between BMI and QCT-derived proximal hip structure and strength in older men: a cross-sectional study. J Bone Miner Res. 2015;30(7):1301-1308. doi:10.1002/jbmr.2450

32. Papageorgiou M, Sathyaplan T, Schutte R. Muscle mass measures and incident osteoporosis in a large cohort of postmenopausal women. Journal of Cachexia, Sarcopenia and Muscle. 2019;10 (1):131-139.

33. Matijevic R, Harhaji V, Ninkovic S, et al. Relationship between body mass index and osteoporosis. Med Pregl. 2016;69:85-88. doi:10.2298/MPNS16S1085M

34. Compston JE, Watts NB, Chapurlat R, et al. Obesity is not protective against fracture in postmenopausal women: GLOW. The American Journal of medicine. 2011;124(11):1043-1050.

35. Janicka A, Wren TA, Sanchez MM, et al. Fat mass is not beneficial to bone in adolescents and young adults. $J$ Clin Endocrinol Metab. 2007;92(1):143-147. doi:10.1210/jc.2006-0794 
36. Zhao L-J, Liu Y-J, Liu P-Y, Hamilton J, Recker RR, Deng H-W. Relationship of obesity with osteoporosis. J Clin Endocrinol Metab. 2007;92(5):1640-1646. doi:10.1210/jc.2006-0572

37. Chen -Y-Y, Fang W-H, Wang -C-C, et al. Body fat has stronger associations with bone mass density than body mass index in metabolically healthy obesity. PLoS One. 2018;13(11):e0206812. doi:10.1371/journal.pone.0206812

38. Morin S, Tsang JF, Leslie WD. Weight and body mass index predict bone mineral density and fractures in women aged 40 to 59 years. Osteoporos Int. 2009;20(3):363-370. doi:10.1007/s00198-008-0688-x
39. Cohen A, Dempster DW, Recker RR, et al. Abdominal fat is associated with lower bone formation and inferior bone quality in healthy premenopausal women: a transiliac bone biopsy study. J Clin Endocrinol Metab. 2013;98(6):2562-2572. doi:10.1210/jc.2013-1047

40. Chen YY, Fang WH,Wang CC, et al. Body fat has stronger associations with bone mass density than body mass index in metabolically healthy obesity. PLOS One. 2018;13(11):e0206812.

\section{Publish your work in this journal}

The Journal of Multidisciplinary Healthcare is an international, peerreviewed open-access journal that aims to represent and publish research in healthcare areas delivered by practitioners of different disciplines. This includes studies and reviews conducted by multidisciplinary teams as well as research which evaluates the results or conduct of such teams or healthcare processes in general. The journal covers a very wide range of areas and welcomes submissions from practitioners at all levels, from all over the world. The manuscript management system is completely online and includes a very quick and fair peer-review system. Visit http://www.dovepress.com/testimonials. php to read real quotes from published authors. 